\title{
The exceptional Nordic forest fire season 2018 in the context of climate change
}

\author{
A number of large forest fires made headlines in Sweden during the exceptionally warm \\ and dry summer of 2018. Also, in Finland, fire departments were busy with numerous \\ wildfires. It appears that weather conditions in $\mathbf{2 0 1 8}$ were very favourable for the occur- \\ rence of fires. In the future, similar summers are expected to occur somewhat more often.
}

ILARI LEHTONEN, ARI VENÄLÄINEN

Finnish Meteorological Institute

On the one hand, fire is a natural phenomenon in boreal forests and has an essential role in maintaining biodiversity. On the other hand, wildfires pose a threat to property and infrastructure, and even to people's lives. This was recently demonstrated during the exceptionally warm and dry summer of 2018 when several large fires burned almost 25,000 hectares of forest in Sweden (Sjöström and Granström, 2020) with the four largest individual fires burning 8,400 hectares of forest in Kårböle, 3,500 hectares in Lillåsen-Fågelsjö, 2,500 hectares in Trängslet and 850 hectares in Stor-Brättan (Björheden and Johannesson, 2019). It was the largest annual burned area in Sweden in a quarter of a century and firefighters from multiple countries were involved in fighting the fires. Numerous forest fires occurred also in Finland but due to efficient fire suppression measures, the burned forest area remained as low as approximately 1,200 hectares and the largest individual fire burned only 50 hectares of forest in Pyhäranta (Lehtonen and Venäläinen, 2020). Yet, it was the largest annual burned area and most active fire season in Finland since 2006. In addition, other regions in north-western Europe, like the United Kingdom, for instance (Sibley, 2019), were similarly affected by warm and dry weather and experienced numerous wildfires. (a) Temperature anomaly $\left({ }^{\circ} \mathrm{C}\right)$

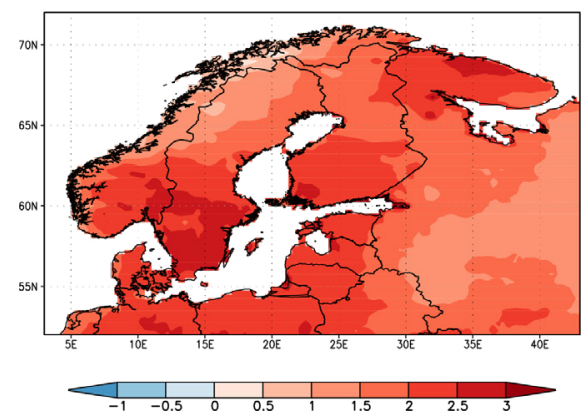

(b) Precipitation anomaly ( $\mathrm{mm} /$ day)

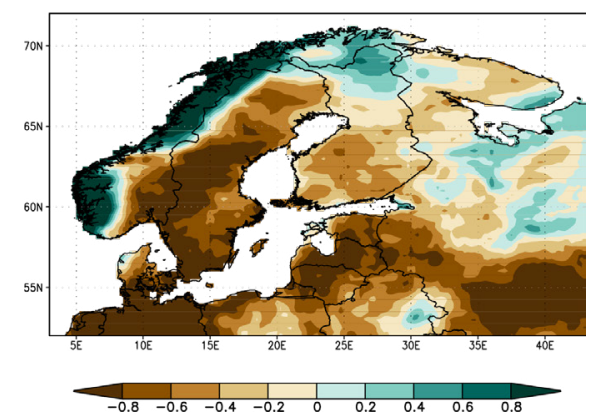

FIG 1: (a) May to September temperature anomaly $\left({ }^{\circ} \mathrm{C}\right)$ in 2018. (b) Precipitation anomaly (mm/day) from May to September in 2018. Anomalies are relative to the period 1979-2019 based on the ERA5 data (Hersbach et al., 2020). Adapted from Lehtonen and Venäläinen (2020).

Climate change is predicted to dramatically alter the fire regime in the circumboreal region (e.g., Kasischke and Stocks, 2012). In general, increasing temperatures leading to enhanced evaporation are expected to increase the fire risk. As the summer of 2018 was roughly as warm as a majority of summers might be in the late 21st century according to the climate projections (Lehtonen and Pirinen, 2019), an interesting question is whether forest fire seasons as in 2018 would also occur more regularly in the future.

In 2018, the mean May to September temperature was in most of northern Europe approximately $2{ }^{\circ} \mathrm{C}$ above the long-term average (Fig. 1a). At the same time, precipitation levels were considerably below the aver- age in all the regions adjacent to the Baltic Sea (Fig. 1b). Already May was very dry and the warmest on record in many places. The most intense heat wave took place during the latter half of July (Sinclair et al., 2019). This was also the time when the largest fires occurred.

In order to evaluate the fire risk related to these warm and dry conditions, we applied the Fire Weather Index (FWI) system following Van Wagner and Pickett (1985). The FWI system, developed originally in Cana$\mathrm{da}$, is one of the most widely used fire risk rating systems worldwide, and for the Finnish conditions, it has proven to perform approximately as well as the forest-fire index that is used operationally in Finland (Vajda et al., 2013). 
The FWI rating is a dimensionless quantity indicating the likely intensity of a fire. It can be further converted into daily severity rating (DSR) that is expected to reflect the required efforts for fire suppression more accurately than FWI by emphasizing higher FWI values through a power relation as follows:

$$
\mathrm{DSR}=0.0272 \times \mathrm{FWI}^{1.77}
$$

DSR, averaged over a certain time period, is called a seasonal severity rating (SSR) which is generally used in evaluating the severity of a fire season. By using the ERA5 reanalysis data (Hersbach et al., 2020), we calculated SSRs averaged from May to September for the period 1979-2019 over northern Europe. Then, we defined the return levels for SSRs according to the generalized extreme value (GEV) distribution (Gilleland and Katz, 2005). The analysis indicated that fire risk in 2018 indeed was exceptionally high over large areas of northern Europe (Fig. 2). Over large areas both in Finland and Sweden, including the regions where the largest fires raged, the recurrence interval of such a high seasonally averaged forest-fire risk was more than 50 years. This agrees with the analysis of Sjöström and Granström (2020) showing that the number of days with high fire risk was in large parts of Sweden much higher in 2018 than in any other recent year.

Building on a previous work, we evaluated how climate change is expected to affect recurrence intervals of fire seasons as difficult as 2018 (Lehtonen and Venäläinen, 2020). This inspection was restricted to Finland, since we used the FWI values calculated by Lehtonen et al. (2016) over the Finnish domain under climate projections extending from 1980 to 2099. We used data from five different climate models (listed in Table 1) participating in the Coupled Model Intercomparison Project phase 5 (CMIP5) under the Representative Concentration Pathway (RCP) scenarios 4.5 and 8.5 (van Vuuren et al., 2011). The model data were downscaled on a $0.1^{\circ} \times$

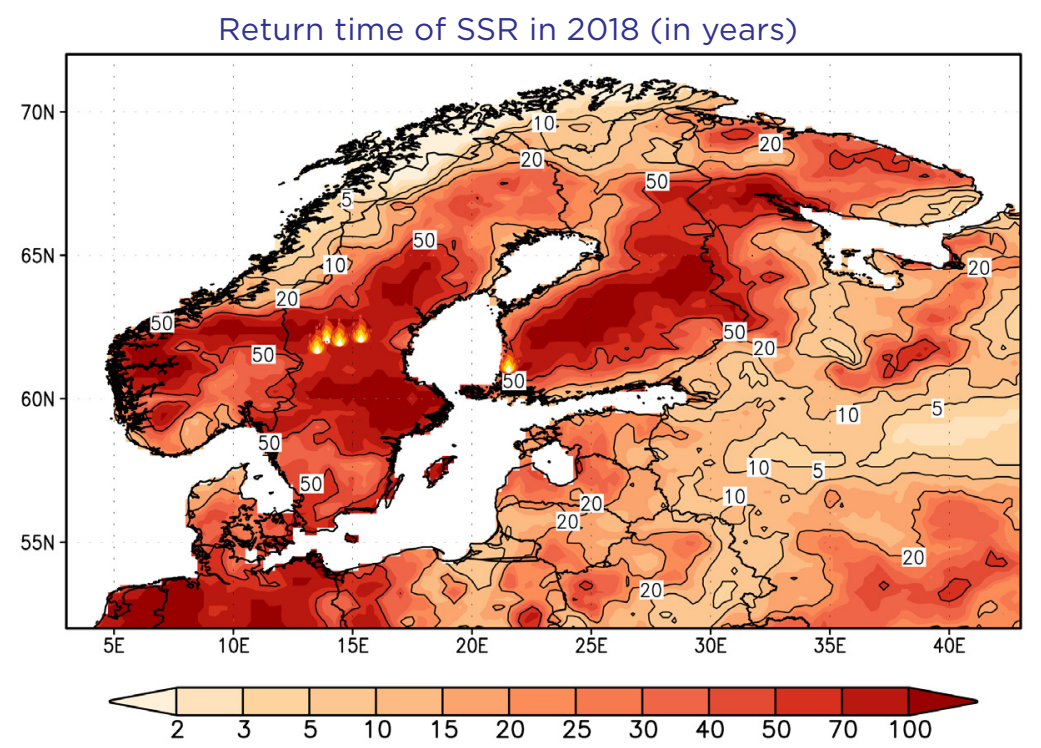

FIG 2: Estimated recurrence interval of the seasonal severity rating (SSR) from May to September in 2018. Bonfire symbols indicate locations of the four largest fires in Sweden and the largest fire in Finland.

\begin{tabular}{|l|l|l} 
MODEL & COUNTRY OF ORIGIN & HORIZONTAL RESOLUTION (LONG $\times$ LAT)
\end{tabular}

\begin{tabular}{l|c|c}
\hline CanESM2 & Canada & $1.875^{\circ} \times 1.875^{\circ}$ \\
\hline CNRM-CM5 & France & $1.4^{\circ} \times 1.4^{\circ}$ \\
\hline GFDL-CM3 & United States & $2.5^{\circ} \times 2.0^{\circ}$ \\
\hline HadGEM2-ES & United Kingdom & $1.25^{\circ} \times 1.875^{\circ}$ \\
\hline MIROC5 & Japan & $1.4^{\circ} \times 1.4^{\circ}$ \\
\hline
\end{tabular}

TABLE 1: CMIP5 models used in this study. For more information about the models, please see Table 9.A.1 in Flato et al. (2013).

$0.2^{\circ}$ latitude-longitude grid covering Finland as described by Lehtonen et al. (2016). We then split the scenario period 1980-2099 into three 40-years periods, 1980-2019, 2020-2059 and 2060-2099, and defined the return levels for SSRs individually for each period and model simulation. The return levels over the model period 1980-2019 were used to match with the return levels calculated from the ERA5 data over the period 1979-2019. For each grid cell in each model simulation, we defined the value of SSR corresponding to the recurrence interval of modelled SSR over the 1980-2019 period matching with the recurrence interval of the SSR in 2018 evaluated from the ERA5 data. Then, we used the recurrence estimates for the two future periods to estimate how often as severe a fire season as in 2018 would occur in the future.

Fig. 3 shows that in the future the recurrence intervals for fire seasons like 2018 are expected to decrease. Nevertheless, according to the multi-model mean estimate, in the near-future period 2020-2059, the recurrence interval remains above 50 years in large areas in central parts of Finland, although this area shrinks compared to the estimated recurrence intervals of the fire season 2018. Also, in the far-future period 2060-2099, the recurrence interval of fire seasons like 2018 is projected 
to remain in most of Finland between 10 and 50 years. Thus, it can be concluded that fire seasons comparable to 2018 will most likely remain quite rare even in forthcoming decades. However, estimated recurrence intervals between the five climate models diverged considerably and the simulations with most pronounced warming indicated much smaller future recurrence intervals for fire seasons like 2018 than the multi-model mean. Moreover, we acknowledge that substantial uncertainty is involved in the return level estimates of larger than 40 years as they exceed the length of the data chunk used in deriving the return levels. Also, the use of only five climate simulations makes a small sample associated with substantial uncertainties. Nevertheless, we conclude that if summer temperatures increase several degrees of Celsius, it is possible that fire seasons comparable to 2018, and even more severe fire seasons, may start to occur frequently.

Acknowledgements: We acknowledge Fire Protection Fund (grant agreement SMDno-2019-988) for the support for this study. We are also grateful for Copernicus Climate Change Service for making the ERA5 reanalysis data available at https:// doi.org/10.24381/cds.adbb2d47. Moreover, we acknowledge the World Climate Research Programme's Working Group on Coupled Modelling, which is responsible for CMIP, and we thank the climate modelling groups (listed in Table 1 of this paper) for producing their

Return time of SSR in 2018 (in years)
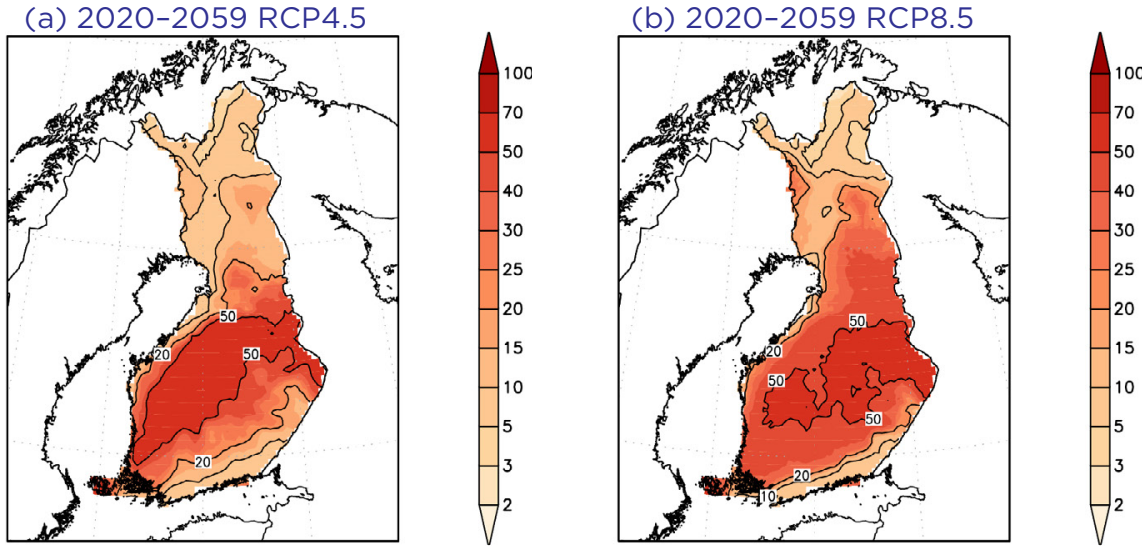

\section{(c) 2060-2099 RCP4.5}
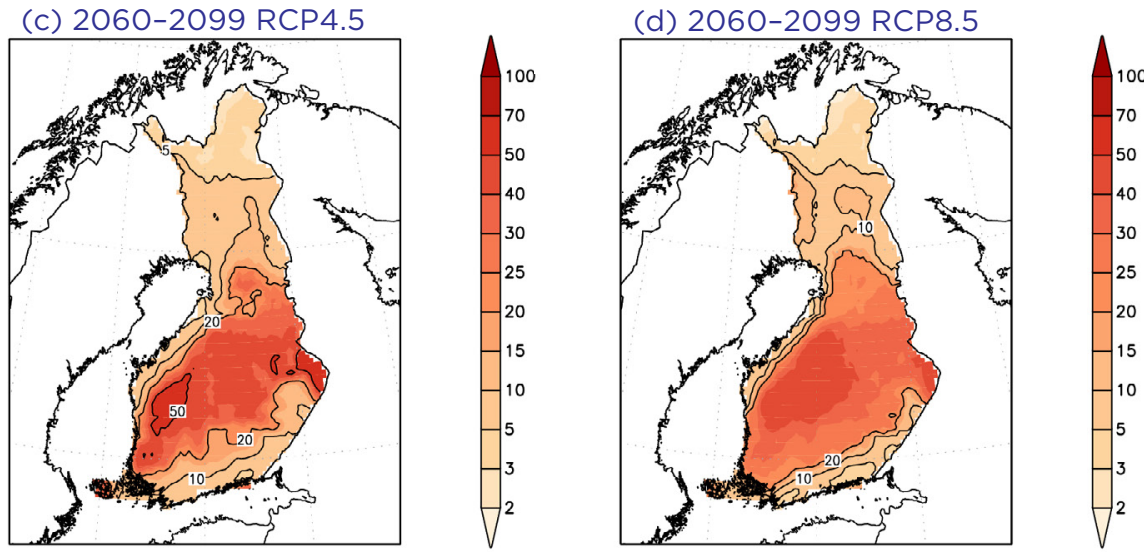

FIG 3: Multi-model mean estimate for the recurrence interval of the seasonal severity rating (SSR) similar to 2018 under the RCP4.5 scenario during 20202059 (a), under the RCP8.5 scenario during 2020-2059 (b), under the RCP4.5 scenario during 2060-2099 (c), and under the RCP8.5 scenario during 20602099 (d). Adapted from Lehtonen and Venäläinen (2020).

model output and making it available. For CMIP, the US Department of Energy's Program for Climate Model Diagnosis and Intercomparison provided coordinating support and led the development of software infrastructure in partnership with the Global Organization for Earth System Science Portals.

Björheden, R., and Johannesson, T., 2019: The effects on Swedish forestry of the summer 2018. Skogforsk, Uppsala. [in Swedish with an abstract in English] Flato, G., et al., 2013: Evaluation of Climate Models. In: Climate Change 2013: The Physical Science Basis. Contribution of Working Group I to the Fifth Assessment Report of the Intergovernmental Panel on Climate Change [Stocker, T. F., et al. (eds.)]. Cambridge University Press, Cambridge, and New York. Gilleland, E., and Katz, R., 2005: Extreme Toolkit (extRemes): Weather and Climate Applications of Extreme Value Statistics. National Science Foundation. Hersbach, H., et al., 2020: The ERA5 global reanalysis. Quart. J. Roy. Meteorol. Soc., 146, 1999-2049.

Kasischke, E. S., and Stocks, B. J., 2012: Fire, Climate Change, and Carbon Cycling in the Boreal Forest. Springer Science \& Business Media, New York. Lehtonen, I., and Pirinen, P., 2019: 2018: An exceptionally warm thermal growing season in Finland. FMI's Clim. Bull. Res. Lett., 1(1), 5.

Lehtonen, I., and Venäläinen, A., 2020: Forest fire season 2018 in a changing climate - an exceptional year or new normal? Finnish Meteorological Institute Reports 2020:2, Helsinki. [in Finnish with an abstract in English]

Lehtonen, I., et al., 2016: Risk of large-scale fires in boreal forests of Finland under changing climate. Nat. Hazards Earth Syst. Sci., 16, $239-253$.

Sibley, A. M., 2019: Wildfire outbreaks across the United Kingdom during summer 2018. Weather, 74, 397-402.

Sinclair, V. A., et al., 2019: The summer 2018 heatwave in Finland. Weather, 74, 403-409.

Sjöström, J., and Granström, A., 2020: Wildfires in Sweden - trends and patterns during recent decades. Swedish Civil Contingencies Agency, Karlstad. [in Swedish with an abstract in English]

Vajda, A., et al., 2013: Assessment of forest fire danger in a boreal forest environment: description and evaluation of the operational system applied in Finland. Meteorol. Appl., 21, 879-887.

van Vuuren, D. P., et al., 2011: The representative concentration pathways: an overview. Clim. Change, 109, 5-31.

Van Wagner, C. E., and Pickett, T. L., 1985: Equations and FORTRAN Program for the Canadian Forest Fire Weather Index System. Canadian Forestry Service, Forestry Technical Report 33, Ottawa. 